\title{
Single-incision Laparoscopic Surgery for Appendiceal Mucoceles: Safety and Feasibility in a Series of 16 Consecutive Cases
}

\author{
Ki Bum Park, Jun Seok Park, Gyu-Seog Choi, Hye Jin Kim, Soo Yeun Park, Jong Pil Ryuk, Won Ho Choi, \\ You Seok Jang ${ }^{1}$ \\ Colorectal Cancer Center, Kyungpook National University Medical Center, Kyungpook National University School of Medicine, Daegu; \\ ${ }^{1}$ Department of Surgery, Pohang St. Mary Hospital, Pohang, Korea
}

Purpose: The aim of this study was to evaluate the technical feasibility, safety, and oncological outcomes of transumbilical single-incision laparoscopic surgery in patients with an uncomplicated appendiceal mucocele.

Methods: A review of a prospectively collected database at the Kyungpook National University Hospital from January 2006 to September 2010 revealed that a series of 16 consecutive patients underwent single-incision laparoscopic surgery (SILS) for an appendiceal mucocele. Data regarding patient demographics, operating time, conversion, surgical morbidity, lateral lymph node status, and mid-term oncologic result were analyzed.

Results: The reported series consisted of 7 women (50\%) and 9 men with a mean age of 61.6 years (range, 41 to 88 years). The mean operative time was 66.8 minutes (range, 33 to 150 minutes). Perioperative mortality and morbidity were $0 \%$ and $6.2 \%$, respectively. Recovery after the procedure was rapid, and the mean hospital stay was 6.8 days (range, 3 to 22 days). Pathology revealed 12 lesions compatible with a mucinous cystadenoma and four others compatible with benign cystic tumors. All surgical margins were clear. In one case, an extra port had to be placed, and another case required conversion from SILS to a standard open laparotomy immediately after identification of the tumor because of a micro-perforation with focal mucin collection. With a median follow-up of 28.7 months, no re-admission or tumor recurrence, such as pseudomyxoma peritonei, was noted in 14 patients.

Conclusion: A single-port laparoscopic mucocelectomy should be safe and feasible and has the advantage of being a minimally invasive approach. Prospective controlled studies comparing SILS and conventional open surgery, with long-term follow-up evaluation, are needed to confirm the author's initial experience.

Keywords: Single-port; Appendiceal mucocele; Laparoscopy; Recurrence

\section{INTRODUCTION}

A mucocele of the appendix is an uncommon pathology, represent-

Received: August 5, 2011 Accepted: October 24, 2011

Correspondence to: Gyu-Seog Choi, M.D.

Department of Surgery, Kyungpook National University Medical Center, Kyungpook National University School of Medicine, 807 Hogukno, Buk-gu, Daegu 702-210, Korea

Tel: +82-53-200-2166, Fax: +82-53-200-2027

E-mail:kyuschoi@mail.knu.ac.kr

(c) 2011 The Korean Society of Coloproctology

This is an open-access article distributed under the terms of the Creative Commons Attribution NonCommercial License (http://creativecommons.org/licenses/by-nc/3.0) which permits unrestricted noncommercial use, distribution, and reproduction in any medium, provided the original work is properly cited. ing $0.2 \%$ to $0.3 \%$ of all appendix specimens [1]. It is often diagnosed clinically as a result of its ability to cause signs and symptoms similar to those of acute appendicitis. If it is asymptomatic, it is often detected as an incidental finding during ultrasonography, computed tomography, radiologic examination of the gastrointestinal tract, or laparotomy. A radically removed appendix is curative in most cases of appendiceal tumors.

The widespread adoption of laparoscopic procedures has occurred since 1987. Initially used in patients with benign disease, laparoscopy has taken on an increasingly larger role in surgery for both benign and malignant indications. In 1997, the mini-laparoscopic cholecystectomy was introduced to further reduce the extent of surgical wounds [2]. More recently, natural orifice transluminal endoscopic surgery (NOTES) has gained much interest as a step 
towards an even less invasive procedure. In both animal and human models, this procedure has shown some success, but it certainly has limitations due to current technology [3-5]. Against this background, single-incision laparoscopic surgery (SILS), also known as laparo-endoscopic single-site surgery (LESS) or transumblical single-port surgery (TUSPS), has emerged as a more feasible, minimally invasive approach. Proposed advantages of single-incision laparoscopic surgery include improved cosmesis, less incisional pain, and easy conversion to a traditional multi-port laparoscopic technique when needed.

In the past decade, single-port laparoscopic surgery has been reported for a number of surgical interventions, including appendectomies, cholecystectomies, and gynecologic procedures [6-11]. Recent reports have examined the immediate outcomes in patients who underwent a single-access colectomy for malignant disease $[12,13]$. However, to our knowledge, there is only 1 case report on single-port laparoscopic resection of an appendiceal mucocele. Thus, this study aimed to assess the safety and the feasibility of the single-port approach for laparoscopic resection of an appendiceal mucocele and to report our initial experience using a surgical glove or SILS multi-port device (SILS Port; Covidien Ltd., Norwalk, CT, USA).

\section{METHODS}

\section{Patients}

The prospectively collected records of 16 consecutive patients with an appendiceal mucocele, who underwent single-incision laparoscopic appendectomy between January 2006 and September 2010, were reviewed retrospectively. All these patients had a radiologically diagnosed appendiceal mucocele. Patient demographics, underlying diseases, surgical data, short-term postoperative outcomes, including complications, and data on local and systemic recurrence, such as pseudomyxoma peritonei, were analyzed.

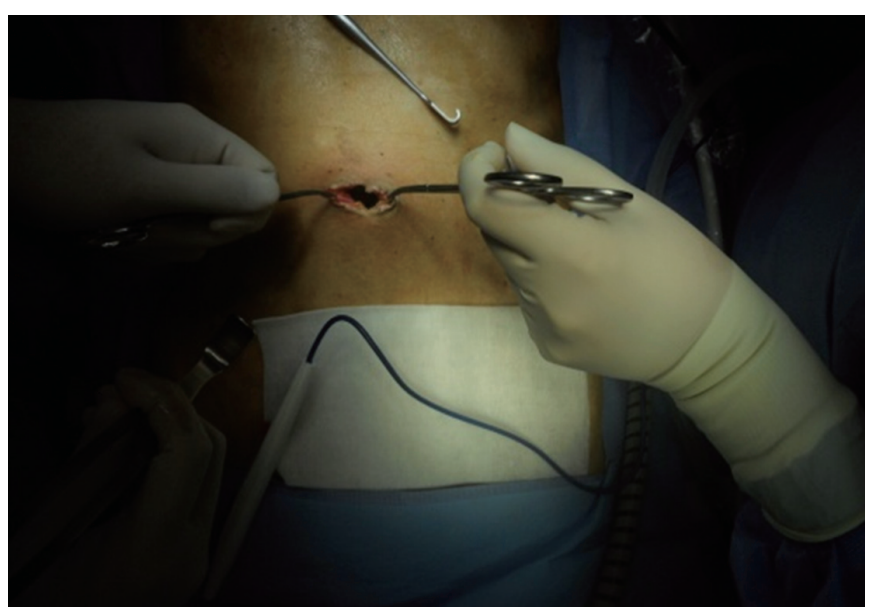

Fig. 1. Intra-umbilical vertical skin incision and rectus fasciotomy to place the single-incision port.
All the procedures were performed by two surgeons (GSC and JSP) for the patients with uncomplicated appendiceal mucoceles. The choice of surgical approach (i.e., laparoscopy, SILS or open surgery) was determined by a preoperative joint decision between the patient and the physician and by intraoperative findings, including the characteristics of the tumor. In general, the SILS mucocelectomy was applied in cases with benign tumors of the cecum. Patients with the following conditions were excluded from SILS: complicated tumors (e.g., complicated with ruptured and mucinous ascites), symptoms suggesting appendicitis, large tumor masses (> 6 $\mathrm{cm}$ ), tumors involving the ascending colon, and intestinal intussusception. All patients received an extensive explanation of the procedure and provided informed consent. This study was approved by the Institutional Review Board of our university. Conversion to open surgery was defined as any extension of the incision required to complete the procedure for reasons other than specimen removal.

During the immediate postoperative period, all patients received self-controlled analgesia (PCA) in the form of intravenous fentanyl. Postoperative recovery pathways were not standardized, but after 1 or 2 days of tolerating a solid diet with no discomfort or complications, the patients were discharged. Patients were followed at 6 month intervals for 2 years and yearly thereafter.

Only descriptive statistics were used in the final analysis. The analysis was performed according to the intention-to-treat principle.

\section{Surgical techniques}

SILS was performed under general anesthesia as follows. The patients were placed in the supine position. The surgeon and the assistant stood on the left side of the patient with the monitor placed on the opposite side. After induction of anesthesia, according to the size of the mucocele and rectus fasciotomy, a $2.0-3.0 \mathrm{~cm}$ completely intra-umbilical vertical skin incision was made to enter the peritoneal cavity (Fig. 1).

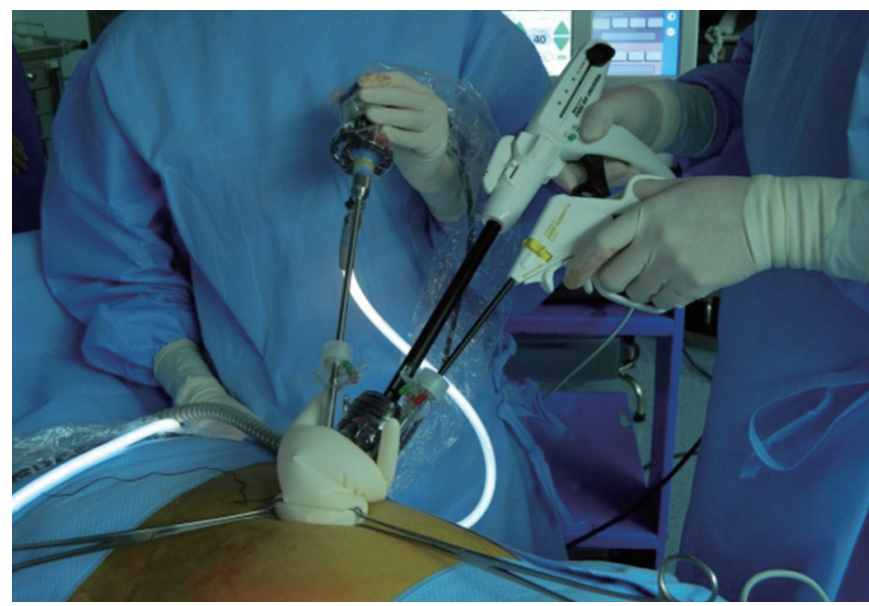

Fig. 2. Actual single-incision port placement. 
For five patients, we used an SILS multiport device (SILS Port). For the remaining patients, we used an extra-small wound retractor and a surgical glove as the "single-port" for securing the working space. The wound retractor was set up through the umbilical incision, and the surgical glove was attached to one 12-mm trocar; two $5-\mathrm{mm}$ trocars were then fixed to the outer ring of the wound retractor (Fig. 2). The abdomen was insufflated to $12 \mathrm{~mm} \mathrm{Hg}$. The patient was then put in the Trendelenburg position, with the left side rotated down. We have routinely used a rigid 30-degree laparoscopic camera system, a standard rigid 5-mm laparoscopic instrument including harmonic scarpel and a $60-\mathrm{mm}$ flexible laparoscopic linear stapler. Once the laparoscope, grasper, and electrical device were in place, the overall procedures were similar to those used in conventional open surgery.

In eight cases, a simple appendectomy was conducted because a short segment of the normal appendix was found distal to its junction with the cecum. This segment was isolated, ligated with an endo-loop, and clipped on both sides before division. On the cecal side, the clipped portion of the appendiceal stump was excised for histologic confirmation of tumor clearance.

In the other eight cases, a partial cecectomy was performed because no segment of the normal appendix existed. The primary surgeon manipulated the mucocele with the use of gravity and the non-traumatic endo-laparoscopic forceps retracting the mesoappendix, thereby reducing the risk of perforation and possible intraperitoneal spillage of mucinous content. Mobilization of the cecum from the lateral wall and division of the mesoappendix were performed using an ultrasurgical shear (Harmonic Scalpel; Ethicon Endo-Surgery Inc., Cincinnanti, OH, USA). Following complete mobilization, the mucocele was moved towards the caudal direction, and partial resection of the cecum was performed intracorporeally by using an Echelon Flex 60 Linear Cutter (Ethicon EndoSurgery Inc.). The specimens were placed within a sterile plastic pouch (Fig. 3), which was retrieved through the umbilical single-

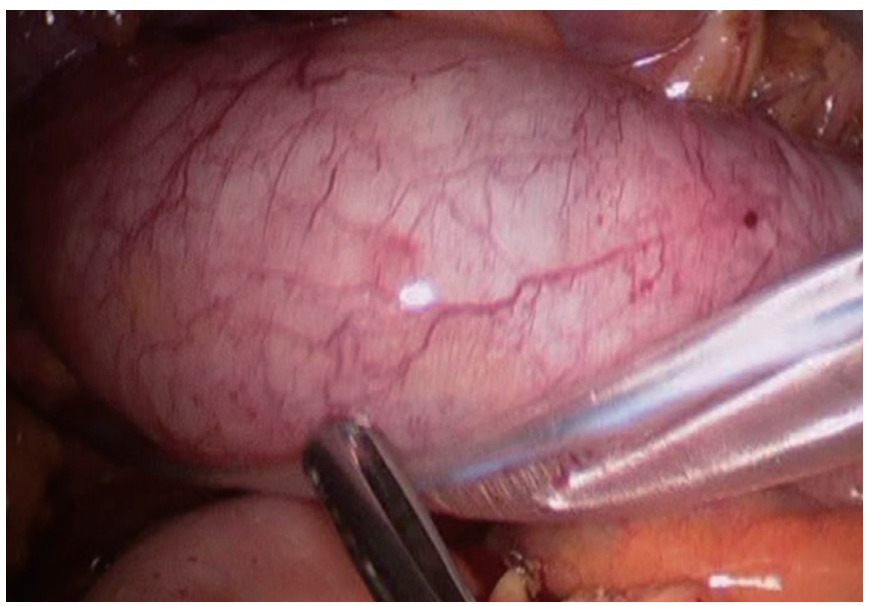

Fig. 3. Specimens within a sterile plastic pouch retrieved through the umbilical single incision site. incision site.

For five patients with a mucocele larger than $5 \mathrm{~cm}$, a $1-2 \mathrm{~cm}$ extension of the fascia was necessary to retrieve the tumor. Because the umbilicus incision was small and the umbilicus was naturally depressed, we usually added an additional stitch in the subcutaneous layer (Fig. 4).

\section{RESULTS}

A total of 34 patients who underwent curative surgery for a mucocele of the appendix between January 2005 and March 2011 in Kyungpook National University Hospital were examined. Of those, $13(38.2 \%)$ patients who underwent conventional multiport laparoscopic excision and 16 (47.0\%) who underwent single-incision laparoscopic appendectomy were enrolled in this study.

The study group (single-port surgery) consisted of 7 women and 9 men with a median age of 61.6 years (range, 41 to 88 years). The mean total operative time for all patients was 68.8 minutes (range, 33 to 150 minutes). Intraoperative spillage of mucinous tumor did not occur in any case.

The pathology showed a mucinous cystadenoma in 12 patients, mucosal hyperplasia in 2 patients, diverticulum with mucinous dilatation in 1 patient, and a low-grade mucinous neoplasm with wall perforation at the tip portion of the appendix in 1 patient. The mean maximum diameter of the cystic tumor for all patients was $3.8 \mathrm{~cm}$ (range, 1.2 to $6.0 \mathrm{~cm}$ ). Passage of flatus was observed after a mean postoperative time of 2.5 days (range, 0 to 4 days). The patients resumed a tolerable diet after a mean postoperative time of 3.8 days (range, 2 to 9 days), and the mean total hospital stay was 6.8 days (range, 3 to 22 days).

Two cases required an extra port or an open laparotomy. In one case, we had difficulty in obtaining an adequate resection margin because a large portion of the mucocele was invaginated into the cecum. After the insertion of one additional 5-mm trocar for cau-

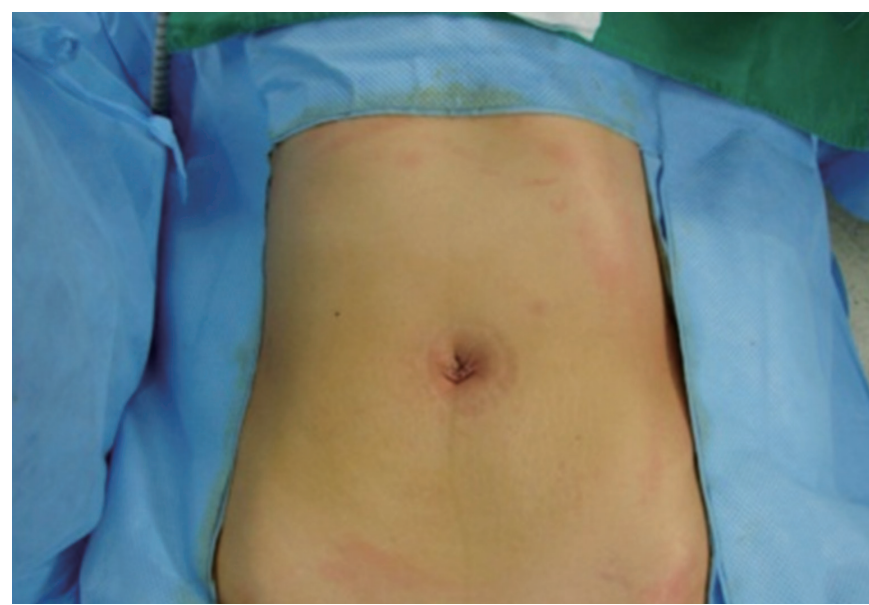

Fig. 4. Postoperative scar from a single-incision laparoscopic appendectomy. 
dal traction of the mucocele, an endoscopic stapling device was used to perform a partial resection of cecum. In the other case, focal perforation of the tip of the mucocele, with focal mucin collection, was identified after the laparoscope had been introduced through the single-port system. Hence, we performed a conventional laparotomy in that patient to prevent further spillage of mucin and to completely resect the mucocele. Following peritonectomy for the affected region, with massive irrigation, a partial cecectomy was performed. There was no mucin collection in the pelvic cavity or the right paracolic gutter area. We did not do any further extensive resection with intraperitoneal chemotherapy in that patient because the postoperative pathologic examination showed low-grade potential for the mucocele.

Postoperative complications were observed in two cases (12.4\%). One case did not initiate oral intake in the early postoperative period due to paralytic ileus. This patient started oral intake on postoperative day 6. Minor umbilical wound complications occurred in another patient and were controlled in the outpatient clinic by using conservative care. Of the 16 patients, two cases were lost to follow-up. At this writing, the mean follow-up period was 28.7 months. No readmission or tumor recurrence, such as pseudomyxoma peritonei, has been noted in the 14 patients still being followed.

\section{DISCUSSION}

A mucocele of the appendix is a relatively infrequent pathology with a reported incidence ranging from 0.2 to $0.3 \%$ of all appendectomy specimens [1]. The reported median age at presentation was 55 years, with a relatively female predominance [14]. The underlying causes of the appendiceal mucoceles included a fecalith, a retention cyst, mucosal hyperplasia, and a mucinous cystadenoma or cystadenocarcinoma [15]. Most cases were asymptomatic, and the lesion was incidentally discovered as a cystic mass on radiologic evaluations for other problems. It is often diagnosed clinically as right lower quadrant abdominal pain similar to acute appendicitis, or as a palpable mass, and it was rarely accompanied by gastrointestinal bleeding, ureteral obstruction, and small bowel obstruction. However, when symptoms were present, a cystadenocarcinoma was more likely to be encountered [14].

The diagnosis of the mucocele was a cystic mass with variable internal echogenicity and depended on the contents of the mucocele, which could be thin and watery or thick and gelatinous $[16,17]$. On the computed tomography (CT) findings, mucoceles usually appear in the right lower quadrant as a well-encapsulated cystic mass with a wall of variable thickness. A nodular enhancing lesion in the wall of the mucocele may be a finding suggestive of a malignant cause [17]. The colonoscopic description was a yellowish submucosal mass with the 'volcano sign.' For an uncomplicated mucinous cystadenoma, a simple appendectomy is reliable. If either the cecal wall or ileum is invaded by the tumor or an adequate safety margin cannot be confirmed, a right hemicolectomy may be indi- cated $[1,14]$. In cases where the tumor has ruptured, aggressive removal of all gross spillage, including by means of a bilateral oophrectomy and omentectomy, should be performed after tumor resection. Studies have shown that intraoperative intraperitoneal chemotherapy improves survival in cases of pseudomyxoma peritonei.

The optimal surgical approach for treating an appendiceal mucocele remains controversial, even though the laparoscopic approach has been successfully used to perform appendectomies $[18,19]$. The main concern regarding its use in dealing with mucinous-secreting lesions is the possible spillage of mucin caused by inadvertent rupture of the lesion during operation, which may lead to pseudomyxoma peritonei if the lesion is neoplastic. Some surgeons recommend a conventional open resection to reduce the potential risk of rupture based on a case report showing widespread mucinous pertitoneal carcinomatosis during laparoscopic resection [20]. However, this occurred in only one case report. The laparoscopic approach not only allows diagnostic examination of the peritoneal cavity but also allows an appendectomy to be performed. Since that report, more surgeons have reported successful laparoscopic management of an appendiceal mucocele in the English literature $[21,22]$. Laparoscopy has been successfully performed by manipulating the lesion carefully without grasping the mucocele. A faster recovery and lower postoperative complication rates have been achieved through this approach. In terms of oncologic result, patients with an appendiceal cystadenoma also showed an excellent survival rate of more than $90 \%[14,23]$.

A one-step farther improvement on conventional laparoscopy, SILS, has been reported for a number of surgical interventions, including appendectomies, cholecystectomies, and gynecologic procedures [6-11]. SILS may be anticipated to offer the benefits of minimal scarring and pain over conventional laparoscopic surgery. In selected patients, its application included various malignant diseases, and it has shown favorable results with regard to feasibility and safety $[12,13]$. However, to date, no report has demonstrated the feasibility and usefulness of this approach for treating an appendiceal mucocele. Case reports have only demonstrated the favorable cosmetic results of this approach, as well as its oncologic safety [24]. To the best of our knowledge, this is the first study on a single-incision laparoscopic appendectomy of an appendiceal mucocele. We included 16 patients diagnosed with an appendiceal mucocele. We successfully performed a single-incision laparoscopic appendectomy in all cases without intraoperative spillage of the mucinous tumor (Table 1). The mean hospital stay was 6.8 days. After surgery for appendiceal mucoceles, we usually prescribe a clear-liquid diet 2 days after surgery, or we delay starting a diet until confirmation of flatus when a patient undergoes a partial cecectomy combined with an appendectomy. Therefore, in our study, the mean hospital stay was longer than that for conventional and single-port laparoscopic appendectomies for benign diseases in previous studies [8]. Minor postoperative complications were observed in only two cases, i.e., postoperative paralytic ileus and a mi- 
Table 1. Clinicopathological characteristics, and perioperative and follow-up data of investigated patients

\begin{tabular}{|c|c|c|c|c|c|c|c|c|c|c|c|c|}
\hline No. & $\begin{array}{l}\text { Age } \\
(y r)\end{array}$ & Sex & $\begin{array}{c}\text { BMl } \\
\left(\mathrm{kg} / \mathrm{m}^{2}\right)\end{array}$ & $\begin{array}{l}\text { Surgical } \\
\text { procedure }\end{array}$ & $\begin{array}{l}\text { Operative } \\
\text { time } \\
\text { (min) }\end{array}$ & Morbidity & $\begin{array}{l}\text { Hospital } \\
\text { stay } \\
\text { (day) }\end{array}$ & $\begin{array}{c}\text { Resection } \\
\text { margin }\end{array}$ & $\begin{array}{c}\text { Tumor } \\
\text { size }(\mathrm{cm})\end{array}$ & Pathology & $\begin{array}{l}\text { Follow-up } \\
\text { duration } \\
\text { (mo) }\end{array}$ & $\begin{array}{c}\text { Recur- } \\
\text { rence/ } \\
\text { metastases }\end{array}$ \\
\hline 1 & 63 & Male & 20.0 & Append. & 67 & None & 6 & CRM & 4.0 & Mucinous cystadenoma & 76 & None \\
\hline 2 & 41 & Male & 23.8 & Append. & 45 & None & 7 & CRM & 1.2 & Mucinous cystadenoma & 72 & None \\
\hline 3 & 43 & Male & 21.4 & Append. with PC & 69 & None & 5 & CRM & 4.0 & Mucosal hyperplasia & NA & NA \\
\hline 4 & 56 & Male & 24.0 & Append. with PC & 50 & None & 6 & CRM & 6.0 & $\begin{array}{l}\text { Diverticulum with } \\
\text { mucinous dilatation }\end{array}$ & 64 & None \\
\hline 5 & 68 & Female & 23.1 & Append. & 30 & None & 7 & CRM & 5.0 & Mucinous cystadenoma & 39 & None \\
\hline 6 & 53 & Male & 26.1 & Append. & 37 & None & 6 & CRM & 4.5 & Mucinous cystadenoma & 25 & None \\
\hline 7 & 55 & Male & 24.4 & Append. with PC & 57 & None & 8 & CRM & 2.5 & Mucinous cystadenoma & 28 & None \\
\hline 8 & 88 & Female & 25.6 & Append. with PC & 102 & lleus & 22 & CRM & 5.5 & Mucinous cystadenoma & NA & NA \\
\hline 9 & 64 & Female & 23.7 & Append. & 66 & None & 8 & CRM & 3.0 & Mucinous cystadenoma & 21 & None \\
\hline 13 & 79 & Female & 26.0 & Append. & 88 & None & 6 & CRM & 6.0 & Mucinous cystadenoma & 11 & None \\
\hline 14 & 59 & Female & 24.3 & Append. with PC & 86 & None & 8 & CRM & 3.0 & Mucinous cystadenoma & 8 & None \\
\hline 15 & 76 & Female & 24.4 & Append. & 106 & None & 8 & CRM & 3.0 & Mucinous cystadenoma & 7 & None \\
\hline 16 & 56 & Male & 23.3 & Append. with PC & 150 & None & 7 & CRM & 3.5 & $\begin{array}{l}\text { Low grade mucinous } \\
\text { neoplasm with wall } \\
\text { perforation }\end{array}$ & 5 & None \\
\hline
\end{tabular}

BMI, body mass index; PC, partial cecectomy; CRM, clear resection margin; NA, not available.

nor umbilical wound complication. Also, there was no readmission or tumor recurrence during follow-up, although the mean followup period of 28.7 months was relatively short. Therefore, in our study, a single-port laparoscopic appendectomy has produced both safe and feasible results, with the supplementary advantage of being a minimally invasive approach.

In our study, only two cases were converted to either open surgery or multi-port conventional laparoscopic surgery. In the first case, an adequate resection margin could not be obtained because a large portion of the mucocele was invaginated into the cecum. We inserted an additional 5-mm trocar for the purposes of traction and adequate endoscopic stapling. In the other case, we converted to open surgery to prevent further spillage of the mucin in a patient with focal perforation of the tip of the mucocele. This condition was not included as an indication for a single-incision laparoscopic appendectomy. Therefore, to obtain oncologic safety, such as adequate resection margin or prevention of mucin spillage, we did not hesitate to convert to open or multi-port laparoscopic surgery. As a result of our effort to maintain oncologic safety in our two complicated cases, no recurrence was shown during the follow-up period. Therefore, to ensure oncologic safety during SILS for patients with appendiceal mucoceles, surgeons have to be cautious about: 1) selecting appropriate patients who do not have symptoms indicating appendicitis; 2) small tumor diameter; 3 ) tu- mor invasion that requires extensive surgery; and 4) aggressive manipulation of tumor-bearing bowel segments. Furthermore, strict tumor size indications for this approach should be determined in future studies.

In conclusion, from this preliminary study, we found that laparoscopic surgery may be a surgical option for treating an appendiceal mucocele because this approach provides good surgical information about the peritoneal cavity without requiring a large incision, comparable oncologic outcomes and earlier recovery. A onestep farther improvement on conventional laparoscopy, a singleincision laparoscopic appendectomy for treating an appendiceal mucocele, seems to be a more useful, minimally invasive alternative to the open or conventional multiport laparoscopic approach in terms of better cosmetic results and comparable perioperative and oncologic results. However, in cases where obtaining an adequate resection margin is difficult or preventing further spillage of the mucin due to a perforation of the mucocele is necessary, we keep in mind converting to either open or multi-port laparoscopic surgery. To confirm the author's initial experience about SILS for treating an appendiceal mucocele, prospective controlled studies comparing SILS and conventional open surgery, with long-term follow-up evaluation, are warranted. 


\section{CONFLICT OF INTEREST}

No potential conflict of interest relevant to this article was reported.

\section{REFERENCES}

1. Higa E, Rosai J, Pizzimbono CA, Wise L. Mucosal hyperplasia, mucinous cystadenoma, and mucinous cystadenocarcinoma of the appendix: a re-evaluation of appendiceal "mucocele". Cancer 1973;32:1525-41.

2. Yuan RH, Lee WJ, Yu SC. Mini-laparoscopic cholecystectomy: a cosmetically better, almost scarless procedure. J Laparoendosc Adv Surg Tech A 1997;7:205-11.

3. Fan JK, Tong DK, Law S, Law WL. Transvaginal cholecystectomy with endoscopic submucosal dissection instruments and singlechannel endoscope: a survival study in porcine model. Surg Laparosc Endosc Percutan Tech 2009;19:29-33.

4. Marescaux J, Dallemagne B, Perretta S, Wattiez A, Mutter D, Coumaros D. Surgery without scars: report of transluminal cholecystectomy in a human being. Arch Surg 2007;142:823-6.

5. Perretta S, Dallemagne B, Coumaros D, Marescaux J. Natural orifice transluminal endoscopic surgery: transgastric cholecystectomy in a survival porcine model. Surg Endosc 2008;22:1126-30.

6. Boruta DM 2nd, Growdon WB, Schorge JO. Single-incision laparoscopic staging for endometrial cancer. J Am Coll Surg 2011;212: e1-5.

7. Chiu CG, Nguyen NH, Bloom SW. Single-incision laparoscopic appendectomy using conventional instruments: an initial experience using a novel technique. Surg Endosc 2011;25:1153-9.

8. Cho MS, Min BS, Hong YK, Lee WJ. Single-site versus conventional laparoscopic appendectomy: comparison of short-term operative outcomes. Surg Endosc 2011;25:36-40.

9. Jung MH, Lee BY. Transumbilical single-port laparoscopic-assisted vaginal hysterectomy via $12-\mathrm{mm}$ trocar incision site. J Laparoendosc Adv Surg Tech A 2011;21:599-602.

10. Khambaty F, Brody F, Vaziri K, Edwards C. Laparoscopic versus single-incision cholecystectomy. World J Surg 2011;35:967-72.

11. Marks J, Tacchino R, Roberts K, Onders R, Denoto G, Paraskeva P, et al. Prospective randomized controlled trial of traditional laparoscopic cholecystectomy versus single-incision laparoscopic cholecystectomy: report of preliminary data. Am J Surg 2011;201:
369-72.

12. O'Connor DJ, Feinberg E, Jang J, Vemulapalli P, Camacho D. Single-incision laparoscopic-assisted right colon resection for cancer. JSLS 2010;14:558-60.

13. Katsuno G, Fukunaga M, Nagakari K, Yoshikawa S, Ouchi M, Hirasaki Y. Single-incision laparoscopic colectomy for colon cancer: early experience with 31 cases. Dis Colon Rectum 2011;54:705-10.

14. Stocchi L, Wolff BG, Larson DR, Harrington JR. Surgical treatment of appendiceal mucocele. Arch Surg 2003;138:585-90.

15. Ronnett BM, Shmookler BM, Diener-West M, Sugarbaker PH, Kurman RJ. Immunohistochemical evidence supporting the appendiceal origin of pseudomyxoma peritonei in women. Int J Gynecol Pathol 1997;16:1-9.

16. Skaane P, Ruud TE, Haffner J. Ultrasonographic features of mucocele of the appendix. J Clin Ultrasound 1988;16:584-7.

17. Horgan JG, Chow PP, Richter JO, Rosenfield AT, Taylor KJ. CT and sonography in the recognition of mucocele of the appendix. AJR Am J Roentgenol 1984;143:959-62.

18. Rampone B, Roviello F, Marrelli D, Pinto E. Giant appendiceal mucocele: report of a case and brief review. World J Gastroenterol 2005;11:4761-3.

19. Liberale G, Lemaitre P, Noterman D, Moerman C, de Neubourg E, Sirtaine N, et al. How should we treat mucinous appendiceal neoplasm? By laparoscopy or laparotomy? A case report. Acta Chir Belg 2010;110:203-7.

20. Gonzalez Moreno S, Shmookler BM, Sugarbaker PH. Appendiceal mucocele: contraindication to laparoscopic appendectomy. Surg Endosc 1998;12:1177-9.

21. Chiu CC, Wei PL, Huang MT, Wang W, Chen TC, Lee WJ. Laparoscopic resection of appendiceal mucinous cystadenoma. J Laparoendosc Adv Surg Tech A 2005;15:325-8.

22. Behranwala KA, Agarwal T, El-Sharkawi D, Shorvon D, Chang A. Laparoscopic resection of mucinous cystadenoma of appendix: a careful decision. Surg Laparosc Endosc Percutan Tech 2006;16: 347-8.

23. Soweid AM, Clarkston WK, Andrus CH, Janney CG. Diagnosis and management of appendiceal mucoceles. Dig Dis 1998;16:183-6.

24. Ishibashi K, Okada N, Ohsawa T, Kumamoto K, Haga N, Ishida H. A simple and safe technique for performing single-port laparoscopic resection of appendiceal mucocele. Tech Coloproctol 2011; 15:341-3. 